\title{
Cultural adaptation and validation of the Neuropathy - and Foot Ulcer - Specific Quality of Life instrument (NeuroQol) for Brazilian Portuguese - Phase $1^{1}$
}

\author{
Antonia Tayana da Franca Xavier ${ }^{2}$ \\ Milton Cesar Foss ${ }^{3}$ \\ Wilson Marques Junior ${ }^{4}$ \\ Claudia Benedita dos Santos ${ }^{5}$ \\ Patricia Toscano Barreto Nogueira Onofre ${ }^{6}$ \\ Ana Emilia Pace ${ }^{7}$
}

This methodological study aimed to adapt the Neuropathy - and Foot Ulcer - Specific Quality of Life instrument - NeuroQol to Brazilian Portuguese and to analyze its psychometric properties. Participants were 50 people with peripheral diabetic neuropathy and foot ulcers. The floor and ceiling effects, the convergent and discriminant validity and the reliability were analyzed. The Cronbach's alpha coefficient was used to test the reliability and the Pearson's correlation coefficient to estimate the convergent validity, the Student's t test was used to evaluate the discriminant validity in the comparison of the NeuroQol scores between participants with and without ulcers. Floor and ceiling effects were found in some domains of the NeuroQol. The reliability was satisfactory. The correlations between the domains of the NeuroQol and the SF36 were negative, significant and of moderate to strong magnitude. The findings show that the Brazilian version of the NeuroQol is reliable and valid and may be employed as a useful tool for improving nursing care for people with DM.

Descriptors: Diabetes Mellitus; Validation Studies; Quality of Life; Diabetic Neuropathies; Diabetic Foot.

\footnotetext{
${ }^{1}$ Paper extracted from Master's Dissertation "Adaptação cultural e validação do Instrumento 'Neuropathy and Foot Ulcer - Specific Quality of Life (NeuroQol)' para o Brasil - Fase 1" presented to Escola de Enfermagem de Ribeirão Preto, Universidade de São Paulo, WHO Collaborating Centre for Nursing Research Development, SP, Brazil.

${ }^{2}$ RN, M.Sc. in Nursing. E-mail: tayanaxavier@uol.com.br.

3 Physician, Ph.D. in Medical Clinic, Full Professor, Faculdade de Medicina de Ribeirão Preto, Universidade de São Paulo, SP, Brazil. E-mail: mcfoss@fmrp.usp.br.

${ }^{4}$ Physician, Ph.D. in Medicine, Associate Professor, Faculdade de Medicina de Ribeirão Preto, Universidade de São Paulo, SP, Brazil. E-mail: wmjunior@fmrp.usp.br.

${ }^{5}$ Statistician, Ph.D. in Statistics, Associate Professor, Escola de Enfermagem de Ribeirão Preto, Universidade de São Paulo, WHO Collaborating Centre for Nursing Research Development, SP, Brazil. E-mail: cbsantos@eerp.usp.br.

${ }^{6}$ Physician, Hospital das Clínicas, Faculdade de Medicina de Ribeirão Preto, Universidade de São Paulo, SP, Brazil. E-mail: patytosc@rnp.fmrp.usp.br.

7 RN, Ph.D. in Nursing, Associate Professor, Escola de Enfermagem de Ribeirão Preto, Universidade de São Paulo, WHO Collaborating Centre for Nursing Research Development, SP, Brazil. E-mail: aepace@eerp.usp.br.
} 


\section{Adaptação cultural e validação do Neuropathy - and Foot Ulcer - Specific Quality of Life (NeuroQol) para a língua portuguesa do Brasil - Fase 1}

Trata-se de estudo metodológico que teve como objetivos adaptar o Neuropathy - and Foot Ulcer - Specific Quality of Life - NeuroQol para a língua portuguesa do Brasil, e analisar suas propriedades psicométricas. Participaram 50 pessoas com neuropatia diabética periférica e úlceras nos pés. Foram analisados os efeitos floor e ceiling, a validade convergente, a discriminante e a confiabilidade. Foi utilizado o coeficiente alfa de Cronbach para testar a confiabilidade e o de correlação de Pearson para estimar a validade convergente; o teste t-Student foi empregado para avaliar a validade discriminante, na comparação dos escores do NeuroQol entre os participantes com e sem úlceras. Constataram-se efeitos floor e ceiling em alguns domínios do NeuroQol. A confiabilidade foi satisfatória. As correlações entre os domínios do NeuroQol e SF-36 foram negativas, significativas, de moderada a forte magnitude. Os achados evidenciam que a versão brasileira do NeuroQol é confiável e válida, e que ele poderá ser utilizado como ferramenta útil para melhoria da assistência de enfermagem para as pessoas com DM.

Descritores: Diabetes Mellitus; Estudos de Validação; Qualidade de Vida; Neuropatias Diabéticas; Pé Diabético.

\section{Adaptación cultural y validación del Neuropathy - and Foot Ulcer - Specific Quality of Life (NeuroQol) para el idioma portugués de Brasil - Fase 1}

Estudio metodológico que tuvo como objetivos adaptar el Neuropathy - and Foot Ulcer - Specific Quality of Life - NeuroQol para el idioma portugués de Brasil y analizar sus propiedades psicométricas. Participaron 50 personas con neuropatía diabética periférica y úlceras en los pies. Fueron analizados los efectos floor y ceiling, la validez convergente, la discriminante y la confiabilidad. Fue utilizado el coeficiente alfa de Cronbach para comprobar la confiabilidad y la correlación de Pearson para estimar la validez convergente; el test t-Student fue empleado para evaluar la validez discriminante en la comparación de los puntajes del NeuroQol entre los participantes con y sin úlceras. Se constataron efectos floor y ceiling en algunos dominios del NeuroQol. La confiabilidad fue satisfactoria. Las correlaciones entre los dominios del NeuroQol y SF-36 fueron negativas, significativas, de moderada a fuerte magnitud. Los hallazgos evidencian que la versión brasileña del NeuroQol es confiable y válida y podrá ser utilizado como una herramienta útil para la mejoría de la asistencia de enfermería para las personas con DM.

Descriptores: Diabetes Mellitus; Estudios de Validación; Calidad de Vida; Neuropatías Diabéticas; Pie Diabético.

\section{Introduction}

Diabetes mellitus (DM) has emerged among the chronic degenerative diseases due to its growing prevalence and the increased morbidity and mortality associated with the disease ${ }^{(1)}$. The prevalence of DM in the urban population, in the age group 30 to 69 years, from 1986 to 1988 was $7.6 \%{ }^{(2)}$ and after approximately nine years, a study conducted in the city of Ribeirão Preto-SP, using similar methods, indicated a prevalence of $12.1 \%{ }^{(3)}$. A recent study ${ }^{(4)}$, performed in the same city in 2006 , showed a prevalence of $15.02 \%$. Associated with the increased prevalence of DM there was also an increase in the number of people with chronic DM 
complications and of premature deaths, mainly from cardiovascular disease(5).

The chronic hyperglycemia of diabetes is associated with long-term damage, dysfunction and failure of various organs, especially the eyes, kidneys, nerves, heart and blood vessels( ${ }^{(6)}$. In the context of the morbidities associated with DM, Diabetic Peripheral Neuropathy (DPN) is one of the chronic complications of high prevalence, affecting $60 \%$ of people with Diabetes Mellitus, and is considered the most important precursor of plantar ulcers and amputations of feet in this group of people ${ }^{(7-8)}$. The neurological dysfunction starts in the distal portions of the peripheral nervous system (usually the feet) and can extend to the upper limbs ${ }^{(9)}$. The impairment of the motor nerves of the lower limbs in people with DM determines muscular hypotrophy, deformities and abnormal pressure points; the impairment of the sensory nerves manifests as sensitivity of the extremities and can progress to anesthesia(10).

The clinical manifestations associated with DPN, as well as its main consequences (ulcers and amputations of the lower limb extremities) may compromise the quality of life ( $Q \circ L)$ of people with $\mathrm{DM}^{(11)}$. Therefore, the development of an instrument to evaluate the Health-Related Quality of Life (HRQoL) of people with DM and neuropathy evidences, by means of its domains (pain, loss/reduction of sensitivity, diffuse sensory-motor symptoms, limitations in daily activities, interpersonal problems and emotional distress), the factors that could jeopardize the HRQoL, specifically of these people(12).

The evaluation of HRQoL directed toward health problems, such as DPN among people with DM, is essential to identify the needs and specific interventions and, therefore, to promote effective solutions to minimize injuries and to prevent future ones. However, studies evaluating HRQOL focused on the effects of DPN are still incipient ${ }^{(13)}$ and, in the national literature, do not identify specific instruments for this purpose. Therefore, when considering DPN as a complication of severe morbidity, the need becomes clear to provide a specific measure of HRQOL for people with DM, DPN and foot ulcers. Thus, the aim of this study was to perform the adaptation of the NeuroQol - Neuropathy and Foot Ulcer - Specific Quality of Life instrument for the Brazilian Portuguese language, as well as to test the reliability and validity of the Brazilian version when used on people with DM in the presence of DPN and foot ulcers.

\section{Methods}

This methodological adaptation and validation study of the instrument NeuroQol(12), considered the first phase of the validation process, consists of the initial analysis of the psychometric properties of the adapted version. It was developed in two steps, the cultural adaptation and the verification of the initial psychometric properties of the instrument. The NeuroQol is a multidimensional scale, developed in the UK and the USA, composed of 35 items. Of these, 27 items evaluate the HRQoL in relation to six domains of the life of a person: Pain (seven items), loss/reduction of sensitivity (three items), diffuse sensory-motor symptoms (three items), limitations in daily activities (three items), interpersonal problems (four items), and emotional distress (seven items). There is one item at the end of each domain, which evaluates, in general, the effects of the domain on HRQoL (items A, B, C, D, E and F), totaling six items. There are also two final items in the scale that evaluate, respectively, the impact of foot problems on HRQoL and the general classification of the HRQoL.

The NeuroQol allows people to respond with the frequency of the symptoms or how the foot problems have affected their HRQoL over the previous four weeks, marking an $X$ on the scale of one to five. Depending on the type of question, the number one represents a "never or hardly at all", and the number five "all of the time or a lot, such as exemplified below. After marking the response to a particular item, the participants were asked to also mark how much the contents of that item represents a discomfort or how important it is, on a scale of one to three, with a response of $1=$ not at all, $2=a$ little, and $3=a \operatorname{lot}^{(12)}$. To obtain the weighted scores for each item of the respective domains, the value obtained on each item (1-5) is multiplied by the value assigned to the corresponding discomfort/importance (1-3). This multiplication provides the degree of impact of the items which compose the instrument. The total values of the scores in each domain are calculated by the mean of the weighted items of the respective domains and can vary from 1 to 15 , i.e. the highest value corresponds to a reference of poor HRQoL.

\section{Step 1: Adaptation of the instrument}

For the adaptation study of the instrument, authorization was requested from the authors ${ }^{(12)}$ of the original version, following the methodological steps ${ }^{(14)}$ that comprise the translation into the target language, i.e. the assessment of this version by a Committee 
of Judges for evaluation of the semantic, idiomatic, conceptual and cultural equivalence, the backtranslation for the analysis of the authors of the instrument and, finally, the semantic analysis with 18 people from the target population who were not part of the sample studied.

The translation was performed by two Brazilians, one an English Language teacher and one that works in the area of translation of health issues, after being informed about the aims of the study. This step resulted in two versions in Portuguese: called the translated Portuguese versions, TPV1 and TPV2. The translated Portuguese versions were compared by the researchers in order to select the phrases of best expression and, as a result of this step, a consensus version was created in Portuguese called Consensual Portuguese Version 1 (CPV1). The next step was the backtranslation, performed by two independent translators, fluent in English, to create the American English version. These translators were not aware of the objectives of the study and were not familiar with the original version of the instrument. Each produced an English version, called the English Version 1 and English Version 2, (EV-1 and EV-2). After the creation of the versions there was a meeting with the translators and one of the researchers, where the aims of the study were presented, the two versions compared and a Final English Version (FEV) of the instrument obtained. Following this a copy of the original instrument was given to each of the translators, to make comparisons with FEV. At this point, each part of the instrument (instructions, items and scale of responses) was read, and the translations made were evaluated seeking one that was more appropriate regarding the conceptual and cultural equivalence, thus resulting in the Consensual Portuguese Version 3 (CPV-3). After completion of these steps, the Final English Version was sent, via e-mail, to the principle author of the instrument, to evaluate the retroversion of the instrument. The author was in agreement and, therefore, it was possible to continue to the next stages of the study.

The Brazilian version was submitted to semantic analysis, evaluated by 18 people with DM. From a committee of specialists (five of them working in the areas of diabetes mellitus, one in the area of diabetic ulcers, one in the area of measurement instruments and one in the area of quality of life; a bilingual translator and a person with DM and higher education) the evaluation of semantic, idiomatic, cultural and conceptual equivalence of each item was requested. The judges made semantic adaptations from English to Brazilian Portuguese, allowing for the appropriateness of use in Brazil. Following this evaluation of the revised version, the instructions of the instrument were modified, along with other minimal changes related to the placement of prepositions before each item of the instrument (by, at). This last version was submitted to semantic analysis(15), which enabled the detection of difficulty in understanding the item "Do you have a paid job?" which was modified to "Do you receive wages for your work?" and became comprehensible after reapplication. Overall, the instrument was easily comprehended by the participants in the semantic analysis and there were no other changes suggested.

\section{Step 2: Verification of the initial psychometric properties of the instrument}

In this step, between October 2009 to May 2010, 50 people $^{(16)}$ in followed up at the Diabetes Outpatient Clinic of a Teaching Hospital and Teaching Health Center in São Paulo State, responded to the instrument. People were included with diabetes mellitus type 1 (DM1) or diabetes mellitus type 2 (DM2), who had DPN or foot ulcers, of both sexes, aged over 18 years, with no other advanced-stage chronic complications and with the cognitive ability to respond to the questions of the instrument.

To test the convergent validity, the instrument used was "Perceived Health Status" (SF-36) (Medical Outcomes Study 36 - Item Short-Form Health Survey)(17), in its version adapted to Portuguese ${ }^{(18)}$ and to assess the validity, two distinct groups were formed: one group of people with ulcers and the other without ulcers. The diagnosis of DPN was by electromyography, performed by the neurology physician. The people with foot ulcers were identified through the follow-up appointment records of their respective units. The participants responded to the Brazilian versions of the NeuroQol and the SF-36(18), at the same time, through individual interviews. Information on the sociodemographic and clinical characteristics of the people were also collected through interviews and consultation with the medical records of the participants. Those excluded were people with other comorbidities that could contribute to the development of neuropathy, such as hypothyroidism, alcoholism, and leprosy, among others; people with diabetes who presented at least one of the following conditions: undergoing hemodialysis, blindness, presence of sequelae of cerebral vascular accident/ heart failure, previous amputations at any level of the 
lower limb, presence of other disabling complications; and people with difficulties of comprehension of the instruments due to cultural factors.

\section{Statistical procedures}

For the construct validity convergent and discriminant analyses were employed. In the convergent analysis it was chosen to investigate the relationship between the domains of the NeuroQol and those of the SF-36, since these instruments evaluate similar constructs, although with opposite scores, i.e. higher values obtained in the NeuroQol indicate a greater impact of the neuropathy and ulcer on the HRQoL, while higher scores with the application of the SF-36 indicate a better HRQoL. Therefore, negative correlations between the domains of these instruments were expected.

The areas evaluated in the SF-36 are: Functional Capacity - FC (ten items), Physical Aspects - PA (four items), Pain - P (two items), General Health Status - GHS (five items), Vitality - VIT (four items), Social Aspects SA (two items), Emotional Aspects - EA (three items), Mental Health - $\mathrm{MH}$ (five items) and one general question of comparative evaluation between the current general health status and that of one year before. The first four domains (FC, PA, P and GHS) evaluate the physical health, and the last four (VIT, SA, EA and $\mathrm{MH}$ ) the mental health. This separation into two major components, physical and mental, allowing the generic analysis of the two aspects involved, which may present themselves distinctly in diverse pathologies ${ }^{(18)}$. To obtain the scores, the questions should be scored according to predetermined rules. Subsequently, the values of the questions are transformed into scores of eight domains which range in the scale from zero to 100 , where zero corresponds to the worst health status and 100 the best ${ }^{(18)}$.

The analysis of the relationship between the domains of NeuroQol and the Physical and Mental components of the SF-36 (convergent analysis) was carried out using Pearson's linear correlation test, and the results were analyzed according to the following classification: 0.00 to 0.19 - absent or very weak correlation; 0.20 to 0.39 - weak correlation; 0.40 to 0.59 - moderate correlation; 0.60 to 0.79 - strong correlation; 0.80 to 1.00 - very strong correlation(19). For the Discriminant Construct Validity, initially the normality of distribution of the sample means of the scores for each domain of the groups with ulcers and without ulcers was tested using the Kolmogorov-Smirnov test (KS). After confirmation of the normality, the Student's t-test was used to compare the means of the instrument between the with ulcer and without ulcer groups. The reliability of the instrument, with regard to the internal consistency of the items, was estimated by Cronbach's coefficient alpha, considering values between 0.70 and 0.90 to be adequate ${ }^{(20)}$. The presence of floor and ceiling effects were also verified. These occur when more than $15 \%$ of the respondents are concentrated in the minimum or maximum value of the scale(16).

The project was approved by the Research Ethics Committee of Clinical Hospital and Teaching Health Center of the School of Medicine of Ribeirão Preto, University of São Paulo, with permission to access the medical records archive service. All the subjects who agreed to participate in the study signed the Terms of Free Prior Informed Consent, in duplicate.

\section{Results}

Due to the inclusion/exclusion criteria established, the time available for data collection and the need to conduct an examination to confirm the neuropathy, it was not possible to increase the sample size. Therefore, the study sample was composed of 50 people. Among the 50 participants, 18 (54\%) were female. Ages ranged from 29 to 72 years, with a mean of 55.7 (10.1) years and a median of 56 years. With regard to the level of schooling, low levels of schooling were found (70.6\%). When analyzing the duration of DM among participants, a mean of 16.3 (8.2) years of existing with the disease was found. With respect to the body mass index (BMI) of the sample, $78.4 \%$ were in the overweight and obese categories. The participants of this study showed a mean of fasting plasma glucose of $184 \mathrm{mg} / \mathrm{dL}$, and of glycated hemoglobin of $9.9 \%$.

In the description of the scores obtained in the responses to the adapted instrument, for the total measure a mean score of 7.2 (5.2) was obtained, which could vary from 1 to 15 . The domain that obtained the highest mean value was Limitations in daily activities, with 9.9 (4.3), while the lowest was in the domain Pain, with 5.8 (2.6). Regarding the reliability of the adapted version of the NeuroQol, evaluated with the Cronbach's alpha, the value for the total instrument was 0.94. The Cronbach's alpha values in the domains ranged from 0.64 (Pain) to 0.89 (Limitations in daily activities) (Table 1 ). 
Table 1 - Number of items, range obtained, mean, median and Cronbach's coefficient alpha of the NeuroQol domains and of the total score for the study sample $(n=50)$. Ribeirão Preto, SP, Brazil, 2010

\begin{tabular}{lccccc}
\hline \multicolumn{1}{c}{ Domains of the NeuroQol } & No. of items & $\begin{array}{c}\text { Range obtained for the } \\
\text { mean score } \\
\text { (Min - Max) }\end{array}$ & Median & Mean (sd)* & Cronbach's alpha \\
\hline NeuroQol total & 35 & $1-15$ & 6.8 & $7.2(5.2)$ & 0.94 \\
Pain & 7 & $1-12$ & 5.5 & $5.8(2.6)$ & 0.64 \\
Loss/reduction in sensitivity & 3 & $1-15$ & 7.1 & $7.3(4.8)$ & 0.76 \\
Diffuse sensory-motor symptoms & 3 & $1-15$ & 8.6 & $7.6(4.4)$ & 0.70 \\
Limitations in daily activities & 3 & $1-15$ & 12.0 & $9.9(4.3)$ & 0.89 \\
Interpersonal problems & 4 & $1-14$ & 6.2 & $6.7(3.9)$ & 0.86 \\
Emotional distress & 7 & $1-15$ & 8.4 & $7.9(4.6)$ & 0.88 \\
\hline
\end{tabular}

*sd: standard deviation

The evaluation of the internal consistency of the items in each domain of the NeuroQol, through the Cronbach's alpha coefficient, obtained values greater than 0.93. The Pearson's product moment correlation test was used to verify the intercorrelations between each item of the instrument, with the total of the scale, and the alpha values, when each item was excluded, i.e. analysis of the extent of the negative or positive impact of the Cronbach's Coefficient on the performance of the scale (Table 2).

Table 2 - Item-total correlation coefficients and Cronbach's alpha for the items of the NeuroQol when each of the items was excluded. Ribeirão Preto, SP, Brazil, 2010

\begin{tabular}{|c|c|c|}
\hline NeuroQol ( $\alpha$ total=0.94) & $\begin{array}{l}\text { Item-total } \\
\text { Correlation }\end{array}$ & $\begin{array}{l}\text { Cronbach's alpha } \\
\text { if item excluded }\end{array}$ \\
\hline 1. Burning in your legs or feet. & 0.84 & 0.947 \\
\hline 2. Excessive heat or cold in your legs or feet. & 0.47 & 0.944 \\
\hline 3. Pins and pricks in your legs or feet. & 0.40 & 0.944 \\
\hline 4. Acute or piercing pain in your legs or feet. & 0.35 & 0.945 \\
\hline 5. Pounding in your legs or feet. & 0.43 & 0.944 \\
\hline 6. Feelings in your legs or feet that make them jump. & 0.47 & 0.944 \\
\hline 7. Skin irritation caused by something in contact with your feet, sheets or socks, for example. & 0.10 & 0.947 \\
\hline A. Have these painful symptoms diminished your quality of life? & 0.87 & 0.946 \\
\hline 8. Numbness in your feet. & 0.83 & 0.940 \\
\hline 9. Inability to feel the difference between hot and cold with your feet & 0.77 & 0.940 \\
\hline 10. Inability to feel objects with your feet. & 0.66 & 0.942 \\
\hline B. Have these last three symptoms diminished your quality of life? & 0.85 & 0.946 \\
\hline 11. Weakness in your hands. & 0.45 & 0.944 \\
\hline 12. Balance problems or instability when walking. & 0.51 & 0.943 \\
\hline 13. Balance problems or instability when standing. & 0.50 & 0.943 \\
\hline C. Have these last three symptoms diminished your quality of life? & 0.74 & 0.946 \\
\hline 14. Ability to do your job. & 0.74 & 0.941 \\
\hline 15. Ability to do housework or to garden. & 0.66 & 0.942 \\
\hline 16. Ability to participate in leisure activities. & 0.67 & 0.941 \\
\hline $\begin{array}{l}\text { D. Have these changes in your daily activities, as a consequence of your foot problems, diminished your } \\
\text { quality of life? }\end{array}$ & 0.87 & 0.946 \\
\hline 17. To what extent have your foot problems interfered in your relationships with people close to you? & 0.84 & 0.940 \\
\hline $\begin{array}{l}\text { 18. Did you feel more physically dependent than you would like to on people who are close to you as a } \\
\text { consequence of your foot problems? }\end{array}$ & 0.61 & 0.942 \\
\hline $\begin{array}{l}\text { 19. Did you feel more emotionally dependent than you would like to on people who are close to you as a } \\
\text { consequence of your foot problems? }\end{array}$ & 0.53 & 0.943 \\
\hline 20. Has your role in the family changed as a result of your foot problems? & 0.63 & 0.942 \\
\hline $\begin{array}{l}\text { E. Have these changes in your relationships with other people, as a consequence of your foot problems, } \\
\text { diminished your quality of life? }\end{array}$ & 0.76 & 0.946 \\
\hline 21. People treat me differently from others persons because of my foot problems. & 0.70 & 0.941 \\
\hline
\end{tabular}


Table 2 - continuation

\begin{tabular}{|c|c|c|}
\hline NeuroQol ( $\alpha$ total $=0.94)$ & $\begin{array}{l}\text { Item-total } \\
\text { Correlation }\end{array}$ & $\begin{array}{l}\text { Cronbach's alpha } \\
\text { if item excluded }\end{array}$ \\
\hline 22. I feel older than I really am because of my foot problems. & 0.69 & 0.941 \\
\hline 23. My self-confidence is affected because of my foot problems. & 0.49 & 0.944 \\
\hline 24. My foot problems turn my life into a struggle. & 0.86 & 0.939 \\
\hline 25. I generally feel frustrated because of my foot problems. & 0.91 & 0.938 \\
\hline 26. My foot problems make me feel constrained. & 0.85 & 0.939 \\
\hline 27. I feel depressed because of my foot problems. & 0.84 & 0.939 \\
\hline F. Have these feelings about yourself, because of your foot problems, diminished your quality of life? & 0.73 & 0.946 \\
\hline 28. In general, I would say that my foot problems diminished my quality of life. & 0.80 & 0.946 \\
\hline 29. In general, I would rate my quality of life as & -0.82 & 0.950 \\
\hline
\end{tabular}

The descriptive results of the Brazilian version of the NeuroQol also allowed the evaluation of the concentration of the responses between the participants, which verified the floor and ceiling effects in the sample studied. It was observed that in the domains Loss/reduction of sensitivity and Limitations in daily activities, there was a floor and ceiling effect, respectively (Table 3 ).

Table 3 - Floor and ceiling effects in the responses in the domains of the NeuroQol. Ribeirão Preto, SP, Brazil, 2010

\begin{tabular}{|c|c|c|c|c|}
\hline \multirow{2}{*}{ Domains of the NeuroQol } & \multicolumn{2}{|c|}{ Adapted NeuroQol } & \multicolumn{2}{|c|}{ Original NeuroQol } \\
\hline & $\%$ responses & $\%$ responses & $\%$ responses & $\%$ responses \\
\hline Pain & 2.0 & 2.0 & 14.4 & 0.5 \\
\hline Loss/reduction in sensitivity & 16.0 & 8.0 & 20.4 & 19.0 \\
\hline Diffuse sensory-motor symptoms & 10.0 & 8.0 & 25.5 & 4.4 \\
\hline Limitations in daily activities & 4.0 & 22.0 & 28.4 & 8.3 \\
\hline Interpersonal problems & 2.0 & 4.0 & 28.4 & 8.3 \\
\hline Emotional distress & 4.0 & 4.0 & 20.7 & 1.0 \\
\hline
\end{tabular}

The evaluation of convergent construct validity was verified by the correlation between the NeuroQol scores and the physical and mental components of the SF-36. While the lower SF-36 instrument values reflect a poorer perception of the general health status, in the NeuroQol lower values indicate better QoL. The Pearson correlation coefficients between the measures are presented in Table 3. Negative, statistically significant linear correlations were found of moderate magnitude between the domains Pain and the Mental component $(r=-0.41 ; p<0.01)$; Loss/reduction of sensitivity and the Physical component $(r=-0.45 ; p<0.01)$; Interpersonal problems and the Physical component ( $r=-0.43$; $\mathrm{p}<0.01)$; Interpersonal problems and the Mental component ( $r=-0.49 ; p<0.01)$; Emotional distress and the Physical component $(r=-0.49 ; p<0.01)$, and also negative correlations of strong magnitude between the domains Diffuse sensory-motor symptoms and the Physical component $(r=-0.64 ; p<0.01)$; Limitations in daily activities and the Physical component $(r=0.60)$; Emotional distress and the Mental component ( $r=-0.71$; $p<0.01)$. The other relationships found between the domains of the NeuroQol and the components of the SF36 were of low magnitude and therefore of little value for clinical practice (Table 4).

Table 4 - Pearson correlation coefficients between the domains of the NeuroQol instrument and the components of the SF-36. Ribeirão Preto, SP, Brazil, 2010

\begin{tabular}{lcc}
\hline \multirow{2}{*}{ NeuroQol } & \multicolumn{2}{c}{ SF 36 } \\
\cline { 2 - 3 } & $\begin{array}{c}\text { Physical } \\
\text { component } \\
\text { (PHC) }\end{array}$ & $\begin{array}{c}\text { Mental } \\
\text { component } \\
\text { (MHC) }\end{array}$ \\
\hline Pain & $-0.31^{*}$ & $-0.41^{\dagger}$ \\
Loss/reduction in sensitivity & $-0.45^{\dagger}$ & -0.26 \\
Diffuse sensory-motor symptoms & $-0.64^{\dagger}$ & -0.19 \\
Limitations in daily activities & $-0.60^{\dagger}$ & $-0.37^{\dagger}$ \\
Interpersonal problems & $-0.43^{\dagger}$ & $-0.49^{\dagger}$ \\
Emotional distress & $-0,49^{\dagger}$ & $-0,71^{\dagger}$ \\
\hline
\end{tabular}

$* 0.01<\mathrm{p}<0.05$

${ }^{\dagger} \mathrm{p}<0.01$

The results of the Student's t test application, relative to the discriminant construct validity, are presented in Table 5. 
Table 5 - Comparison of the standardized mean values and respective standard deviations for the domains of the NeuroQol between the with ulcer and without ulcer groups. Ribeirão Preto, SP, Brazil, 2010

\begin{tabular}{|c|c|c|c|c|c|c|}
\hline \multirow{2}{*}{ Domains of the NeuroQol } & \multicolumn{2}{|c|}{ With ulcer group } & \multirow{2}{*}{$\mathbf{p}$} & \multicolumn{2}{|c|}{ Without ulcer group } & \multirow{2}{*}{$\mathbf{p}$} \\
\hline & Mean & sd & & Mean & sd & \\
\hline Pain & 5.6 & 2.6 & 0.58 & 6.0 & 2.6 & 0.58 \\
\hline Loss/reduction in sensitivity & 7.6 & 4.6 & 0.48 & 6.7 & 5.0 & 0.49 \\
\hline Diffuse sensory-motor symptoms & 7.9 & 4.5 & 0.54 & 7.1 & 4.2 & 0.54 \\
\hline Limitations in daily activities & 11.2 & 4.0 & $0.00^{\dagger}$ & 7.7 & 4.0 & $0.00^{*}$ \\
\hline Interpersonal problems & 7.5 & 3.9 & 0.08 & 5.5 & 3.9 & 0.08 \\
\hline Emotional distress & 8.1 & 4.7 & 0.67 & 7.5 & 4.6 & 0.67 \\
\hline
\end{tabular}

$* p<0.01$ Student's t

It was observed that, when comparing the standardized mean values of the domains of the NeuroQol between the with ulcers and without ulcers groups there was a difference between the means in the domain of Limitations in daily activities, which was expected, since people with ulcers have a limited capacity to perform their daily activities, such as doing their work, tasks in the home or garden, and participating in leisure activities, which implies a worse QoL

\section{Discussion}

The sample was determined at 50 participants, which, according to the literature(16), permits the initial evaluation of the psychometric properties of measuring instruments for psychosocial variables. In relation to the sociodemographic characterization, the sample consisted of adults with an mean age of 56 years, low education, with a greater frequency of females, similar to those of other studies conducted in the same location(21-22), which can characterize the profile of people seeking medical care in this unit. However, they differ from the original construction study of the instrument, developed with a population from North America and the United Kingdom, in relation to gender and education. Regarding the results of the adapted instrument, the highest and lowest mean scores were for the domains Limitations in daily activities and Pain, respectively, and in the original study Loss/reduction of sensitivity and Pain ${ }^{(12)}$.

Studies indicate that foot ulcers impact in the physical functioning of people with diabetes and can lead to limitations in daily activities, negatively affecting the quality of life ${ }^{(23-24)}$. Although Pain is the lower scoring domain in the studies cited, it is present in approximately $11 \%$ of people with DPN, and its presence significantly compromises the QoL of people with DM and DPN(25). The internal consistency measured by Cronbach's coefficient alpha of the instrument was 0.94 , a value that can be considered adequate for the validation of instruments $^{(16)}$. The domains which obtained the lowest and highest values for this coefficient were Pain (0.64) and Limitations in daily activities (0.89), respectively. Knowing that Cronbach's alpha values smaller than 0.70 can damage the internal consistency ${ }^{(20)}$, it is clarified that, in this initial phase of the adaptation and validation of the NeuroQol instrument, the sample presented is small for the number of items of the instrument, which justifies the development of a second phase of the study, with a larger number of participants. In relation to the floor and ceiling effects, it was observed in the present study, that they occurred in the domains Loss/ reduction in sensitivity (16.0) and Limitations in daily activities (22.0), respectively. These last psychometric analyses of the present study indicate favorable results in relation to the expected profile for the distribution of responses in a measuring instrument. These effects can harm the responsiveness property of the instrument that relates to the ability to detect changes when the individual improves or worsens ${ }^{(26)}$, that is, the ability of the instrument to detect clinically important changes with the passage of time ${ }^{(16)}$.

In the convergent validity, the linear correlations were negative and statistically significant between all the values of the measurements of the components of the SF-36 instrument and measurements of the domains of the NeuroQol, as expected. While the lower SF-36 instrument values reflect a poorer perception of the general health status, in the NeuroQol lower values indicate a better QoL. In addition, the results showed moderate to strong magnitude correlations between the NeuroQol domains and the SF-36, results similar to the original study ${ }^{(12)}$. The discriminant validity only showed a statistically significant difference between the NeuroQol scores of the two groups in the Limitations in daily activities domain. The literature states that the presence of ulcers can cause greater physical and emotional consequences for the person with diabetes than the symptoms of the neuropathy ${ }^{(23)}$. Thus, it is expected 
that the NeuroQol be able to discriminate the greatest impact of the disease among people with diabetes and ulcers than among those with DM and neuropathy.

Although, the mean scores of the domains, with the exception of Pain, were higher among the people with ulcers, these differences were not statistically significant between the groups studied. For the Pain domain, a significantly higher mean was found among those without ulcers, which could be explained by the presence of pain in the initial stage of the diabetic neuropathy(27). The enlargement of the sample size in subsequent studies is recommended, in order to expand the analysis of discriminant validity between the with and without ulcer groups, as well as the performance of the factor analysis of the instrument in order to verify the relevance of the items in the domains of the instrument in the adapted version.

\section{Final considerations}

The results of this first phase of adaptation and validation allow it to be considered that the NeuroQoL has psychometric properties that permit its use as a valid and reliable instrument. However, a second phase of the study is needed to extend the psychometric evaluation, principally with the coverage of different regions of Brazil, and to consolidate its cultural adaptation and validation. The evaluation of HRQoL is crucial in order to establish interventions for the nursing care of people with DM. However, it is often necessary to recognize the influences of a specific situation of health-illness, in order to direct actions to prevent, identify early and intervene in health injuries which can compromise the biopsychosocial aspects of the person.

\section{References}

1. Schmidt MI, Duncan BB, Silva GA, Menezes AM, Monteiro CA, Barreto SM, Chor D, Menezes PR. Health in Brazil 4. Chronic non-communicable diseases in Brazil: burden and current challenges. Lancet. [periodico na Internet]. 2011;377. [acesso 06 set 2010]. Disponível em: www.diabetes.org.br/attachments/lancet-collection. pdf. DOI:10.1016/S0140-6736(11)60135-9.

2. Malerbi DA, Franco LJ. Multicenter study of the prevalence of diabetes mellitus and impaired glucose tolerance in the urban Brazilian population aged 30-69 Yr. Diabetes Care. 1992;15(11):1509-16.

3. Torquato MTCG, Montenegro RMJ, Viana LAI, Souza RAHG, Lanna CMM, Lucas JCB, et al. Prevalence of diabetes mellitus and impaired glucose tolerance in the urban population aged 30-69 years in Ribeirão Preto (São Paulo), Brazil. São Paulo Med J. 2003;121:224-30.

4. Moraes AS, Freitas ICM, Gimeno SGA, Mondini L. Prevalência de diabetes mellitus e identificação de fatores associados em adultos residentes em área urbana de Ribeirão Preto, São Paulo, Brasil, 2006: Projeto OBEDIARP. Cad Saúde Pública. 2010;26(5):929-41.

5. Wild S, Roglic G, Green A, Sicree R, King H. Global prevalence of diabetes. Estimates for the year 2000 projections for 2030. Diabetes Care. 2004;27(5):1047-53.

6. American Diabetes Association. Diagnosis and classification of diabetes mellitus. Diabetes Care.2008;32(suppl.1):S55-S60.

7. Rathur HM, Boulton AJ. The neuropathic diabetic foot. Nat Clin Pract Endocrinol Metab. 2007;3(1):14-25.

8. Singh N, Armstrong DG, Lipsky BA. Preventing foot ulcers in patients with diabetes. JAMA. $2005 ; 293(2): 217-28$.

9. Schmid H, Neumann C, Brugnara L. O diabetes melito e a desnervação dos membros inferiores: a visão do diabetólogo. J Vasc Br. 2003;2(1):37-48.

10. Porciúncula MVP, Rolim LCP, Garofolo L, Ferreira SBG. Análise de fatores associados à ulceração de extremidades em indivíduos diabéticos com neuropatia periférica. Arq Bras Endocrinol Metab. 2007;51(7):1134-42.

11. Tentolouris N, Petrikkos G, Vallianou N, Zachos C, Daikos GL, Tsapogas $P$, et al. Prevalence of methicillinresistant Staphylococcus aureus in infected and uninfected diabetic foot ulcers. Clin Microbiol Infect. 2006;12(2):186-9.

12. Vileikyte $L$, Peyrot $M$, Bundy $C$, Rubin RR, Leventhal $H$, Mora $P$, et al. The development and validation of a neuropathy- and foot ulcer-specific quality of life instrument. Diabetes Care. 2003;26(9):2549-55.

13. Vileikyte L. Psychological aspects of diabetic peripheral neuropathy. Diabetes Rev. 1999;7:387-94.

14. Ferrer M, Alonso J, Prieto L, Plaza V, Monsó E, Marrades $R$, et al. Validity and reliability of the St George's Respiratory Questionnaire after adaptation to a different language and culture: the Spanish example. Eur Respir J. 1996;9(6):1160-6.

15. Pasquali L. Princípios de elaboração de escalas psicológicas. Rev Psiquiatr Clín. (São Paulo). 1998;25(5):206-13.

16. Terwee CB, Bot SDM, Boer MR, van der Windt DAWM, Knol DL, Dekker J, et al. Quality criteria were proposed for measurement properties of health status questionnaires. J Clin Epidemiol. 2007;60:34-42

17. Ware JE Jr, Sherbourne CD. The MOS 36-item short- 
form health survey (SF-36). I. Conceptual framework and item selection. Med Care. 1992;30(6):473-83.

18. Ciconelli RM, Ferraz MB, Santos W, Meinão I, Quaresma MR. Tradução para a língua portuguesa e validação do questionário genérico de avaliação de qualidade de vida SF-36 (Brasil SF-36). Rev Bras Reumatol. 1999;39:143-50.

19. Swinscow TDV. Statistics at square one. [Internet]. 9a ed. London: Br Med J.Group, 1997. [acesso 1 jun 2009]. Disponível em: http://www.bmj.bmjjournals. com/collections/statsbk/11.dtl

20. Fayers PM, Machin D. Quality of life: assessment, analysis and interpretation. New York: John Wiley; 2000.

21. Pace $A E$, Ochoa-Vigo $K$, Caliri MHL, Fernandes APM. Oconhecimento sobre diabetes mellitus no processo deautocuidado. Rev. Latino-Am. Enfermagem. 2006;14(5):728-34.

22. Villas-Boas LCG, Foss MC, Foss-Freitas MC, Torres $\mathrm{HC}$, Monteiro LZ, Pace AE. Adesão à dieta e ao exercício físico das pessoas com diabetes mellitus. Texto Contexto Enferm. 2011;20(2):272-9.

23. Ribu L, Hanestad BR, Moum T, Birkeland K, Rustoen T. A comparison of the health-related quality of life in patients with diabetic foot ulcers, with a diabetes group and a nondiabetes group from the general population. Qual Life Res. 2007;16(2):179-89.

24. Meijer JWG, Trip J, Jaegers SMHJ, Links TP, Smits AJ, Groothoff JW, et al. Quality of life in patients with diabetic foot ulcers. Disabil Rehabil. 2001;33:336-40.

25. Benbow SJ, Wallymahmed ME, MacFarlane IA. Diabetic peripheral neuropathy and quality of life. $Q \mathrm{~J}$ Med. 1998;91(11):733-7.

26. Fayers PM, Machin D. Quality of life. The assessment, analysis, and interpretation of patient-reported outcomes. 2.ed. Chichester: England John Wiley; 2007. 27. Boulton AJM, Knight G, Drury J, Ward JD. The prevalence of symptomatic diabetic neuropathy in an insulin-treated population. Diabetes Care 1985;8:125-8. 